a

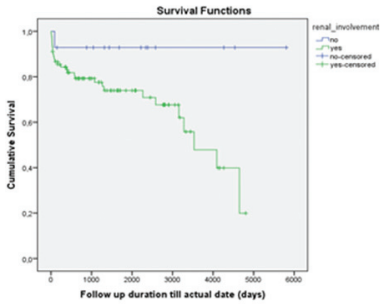

b

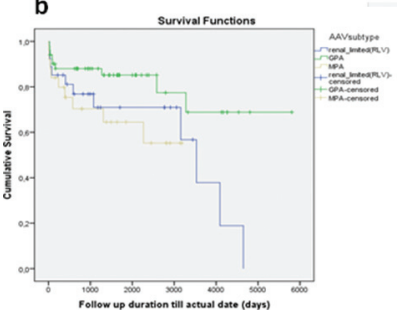

Figure. The results of the Kaplan-Meier analysis. Overall mortality was significantly associated with renal involvement (a) and AAV subgroups (b).

*AAV: ANCA-Associated Vasculitis; GPA: Granulomatosis with PolyAngiitis; MPA: Microscopic PolyAngiitis; RLV: Renal Limited Vasculitis

Disclosure of Interests: Onay Gercik: None declared, Zeki Soypacaci: None declared, Fulya Çakalağaoğlu: None declared, Gokhan Kabadayi: None declared, Idil Kurut: None declared, Dilek Solmaz: None declared, Servet Akar Grant/research support from: MSD, Abbvie, Roche, UCB, Novartis, Pfizer, Amgen, Consultant for: MSD, Abbvie, Roche, UCB, Novartis, Pfizer, Amgen, Speakers bureau: Pfizer

DOI: 10.1136/annrheumdis-2019-eular.4178

\section{FRI0294 CHEMOTHERAPY AND G-CSF INDUCED LARGE VESSEL VASCULITIS AND CAROTIDYNIA - SIX PATIENT CASES AND A SYSTEMATIC LITERATURE REVIEW}

Kirsi Taimen ${ }^{1,1}$, Samu Heino ${ }^{2}$, la Kohonen ${ }^{3}$, Heikki Relas ${ }^{4}$, Riikka Huovinen ${ }^{5}$, Arno Hänninen ${ }^{6}$, Laura Pirilä ${ }^{1} .{ }^{1}$ Turku University Hospital, Rheumatology and Clinical Immunology, Turku, Finland; ${ }^{2}$ University of Turku, Medicine, Turku, Finland; ${ }^{3}$ Turku University Hospital, Radiology, Turku, Finland; ${ }^{4}$ Helsinki University Hospital, Rheumatology, Turku, Finland; ${ }^{5}$ Turku University Hospital, Oncology, Turku, Finland; ${ }^{6}$ University of Turku, Medical microbiology and immunology, Turku, Finland

Background: Large vessel vasculitis (LVV) and neutropenic infection in patients receiving chemotherapy present similar clinical symptoms with fever and high inflammation parameters. Infection is more frequent but LVV should be kept in mind as differential diagnosis. LVV is a serious condition which may lead to vessel wall damage. Published few case reports and adverse event reports suggest causal association between LVV and use of granulocyte colony-stimulating factor (G-CSF) and/or chemotherapy (1).

Objectives: To evaluate the rare connection of LVV and anticancer therapy by describing our six patient cases and a systematic review of the literature.

Methods: Between 2016-2018 we identified six patients with probable drug induced LVV associated with chemotherapy and G-CSF. All patients had breast cancer. Systematic literature review was performed according to PRISMA guidelines using comprehensive search terms for breast cancer, chemotherapy, LVV and G-CSF.

Results: In our case series, 5/6 patients developed LVV symptoms within two weeks after administration of docetaxel and G-CSF. Vasculitis symptoms disappeared after drug cessation or drug change.

Literature search identified 16 published case reports with association of LVV and chemotherapy fulfilling our study criteria. Altogether 22 cases were analyzed. Mean age was 59 years (range 40-77 years). In 14/22 cases data from G-CSF administration was available. Time delay from drug administration to LVV symptoms was average 10 days (range 1-42 days) with G-CSF and median 12 days (range 2-310 days) with chemotherapy. Most prevalent cancer types were breast cancer (8/22), hematological malignancies (7/22) and lung cancer (3/22). Most common clinical LVV symptom were fever (18/22), neck pain (11/22) and chest pain (8/22). Diagnosis was confirmed with imaging studies showing vasculitis in various large vessels in upper body. Notably, four cases had vascular inflammation only in carotid region and this was recognized by radiologist as carotidynia/transient perivascular inflammation of the carotid artery (TIPIC) syndrome.

Conclusion: Large vessel vasculitis is a possible serious rare adverse event associated with chemotherapy (possibly docetaxel) and G-CSF. Since signs and symptoms are non-specific, we assume this condition is underdiagnosed and should be kept in mind when treating oncological patients. Successful management requires early identification and cessation of the drug. When diagnosed and treated properly, the recovery is usually fast.

\section{REFERENCE:}

[1] Lardieri, A., McCulley, L., Christopher Jones, S. \& Woronow, D. Granulocyte colony-stimulating factors and aortitis: A rare adverse event. Am. J. Hematol. 93, E333-E336 (2018).

Disclosure of Interests: Kirsi Taimen Speakers bureau: Pfizer, Novartis, Abbvie, Roche (lectures), Samu Heino: None declared, la Kohonen: None declared, Heikki Relas Speakers bureau: Pfizer, Riikka Huovinen Consultant for: Roche, Amgen, Novartis, Pfizer, Speakers bureau: Roche, Amgen, Novartis, Pfizer, Arno Hänninen Speakers bureau: Roche, Laura Pirilä Consultant for: Abbvie, Novartis, Eli Lilly, MSD Finland, Pfizer, UCB, Roche, Jansen- Cilag, Sandoz, Speakers bureau: Pfizer, DOI: 10.1136/annrheumdis-2019-eular.5009

\section{FRI0295 EVALUATION OF CLINICAL CHARACTERISTICS IN BEHCET SYNDROME BY GENDER AND AGE; A SINGLE CENTER EXPERIENCE WITH 665 PATIENTS}

Murat Torgutalp, Serdar Sezer, Müçteba Enes Yayla, Ayse Bahar Kelesoglu Dincer, Emine Gözde Aydemir Gülöksüz, Didem Sahin Eroglu, Tahsin Murat Turgay, Gülay Kınıklı, Askin Ates. Ankara University Faculty of Medicine, Rheumatology, Ankara, Turkey

Background: To evaluate clinical characteristics according to age and gender in patients with Behcet's Syndrome (BS).

Objectives: BS is a systemic vasculitis that affects mucosa, skin, joint, eye, vessels, gastrointestinal system, and central nervous system. The disease characterizes by relapses and remissions, and it is known that prognosis is worse in young males. The aim of this study was to reinvestigate the relationship between the clinical features of BS according to gender and age.

Methods: The data of 665 patients (282 male, 383 female), diagnosed as BS according to the ISG-1990 Behçet's Disease classification criteria were retrospectively evaluated.

Results: All patients had oral aphthous (OA) ulcers (100\%). Eighty-five percent of patients had a genital ulcer (GU), 56.5\% had erythema nodosum (EN), 65.9\% had papulopustular lesions (PPL), 32.6\% had ocular involvement, $49.3 \%$ had joint involvement, and $21.7 \%$ vascular involvement, and $4.8 \%$ had neurobehcet. The incidence rates of PPL, ocular involvement, and vascular involvement were significantly higher in males ( $p<0.001, p=0.004$ and $p<0.001$, respectively). GU, joint involvement, headache, and pathergy positivity were more common in women $(p=$ $0.006, p<0.001, p<0.001$ and $p<0.001$, respectively). Table 1 shows the comparison of the clinical features according to gender. When we compare the mean age of the patients according to the presence or absence of clinical findings; patients with GU, EN, and vascular involvement were found to be younger than those without $(p=0.006, p=$ 0.025 and $p=0.007$, respectively) (Table-2).

Conclusion: Clinical features of BS may vary according to age and gender. Variations can be observed depending on the size of the population, the center where the study is conducted, and the selected-criteria for inclusion. In our study, PPL, ocular involvement and vascular involvement were more frequent in men, whereas GU, joint involvement, headache, and pathergy positivity were more common in women. In addition, GU, EN, and vascular involvement were related to younger ages. Our results were compatible with the BS literature.

\section{REFERENCES}

None 
Table 1. Characteristics of patients according to gender

\begin{tabular}{|c|c|c|c|c|c|}
\hline Findings & $\begin{array}{l}\text { Patients, } \mathbf{n} \\
(\%)\end{array}$ & $\begin{array}{c}\text { Male } \\
(n=282)\end{array}$ & $\begin{array}{l}\text { Female } \\
(n=383)\end{array}$ & OR $(95 \% \mathrm{Cl})$ & $p$ \\
\hline GU, n (\%) & $571,(85.9)$ & $\begin{array}{c}230 \\
(81.6)\end{array}$ & $341(89)$ & $\begin{array}{l}1.84(1.18- \\
2.85)\end{array}$ & 0.006 \\
\hline EN, n (\%) & $376,(56.5)$ & $\begin{array}{c}151 \\
(53.5)\end{array}$ & $\begin{array}{c}225 \\
(58.7)\end{array}$ & $\begin{array}{c}1.24(0.91- \\
1.69)\end{array}$ & 0.181 \\
\hline PPL, n (\%) & $438,(65.9)$ & $\begin{array}{c}215 \\
(76.5)\end{array}$ & $\begin{array}{c}223 \\
(58.2)\end{array}$ & $\begin{array}{l}0.43(0.30- \\
0.60)\end{array}$ & $<0.001$ \\
\hline Ocular, n (\%) & $217,(32.6)$ & $\begin{array}{c}109 \\
(38.7)\end{array}$ & $\begin{array}{c}108 \\
(28.2)\end{array}$ & $\begin{array}{c}0.62(0.45- \\
086)\end{array}$ & 0.004 \\
\hline Joint involvement, $\mathrm{n}(\%)$ & $328,(49.3)$ & $\begin{array}{c}114 \\
(40.4)\end{array}$ & $\begin{array}{c}214 \\
(55.9)\end{array}$ & $\begin{array}{l}1.87(1.37- \\
2.55)\end{array}$ & $<0.001$ \\
\hline Vascular involvement, $\mathrm{n}(\%)$ & $144,(21.7)$ & $\begin{array}{c}99 \\
(35.1)\end{array}$ & $\begin{array}{c}45 \\
(11.7)\end{array}$ & $\begin{array}{l}0.25(0.17- \\
0.37)\end{array}$ & $<0.001$ \\
\hline GI involvement, $\mathrm{n}(\%)$ & $18,(2.7)$ & $8(2.8)$ & $10(2.6)$ & $\begin{array}{l}0.92(0.36- \\
2.36)\end{array}$ & 0.859 \\
\hline Headache, $(n=581), n(\%)$ & $200(34.4)$ & $46(19)$ & $\begin{array}{c}154 \\
(45.4)\end{array}$ & $\begin{array}{l}3.55(2.41- \\
5.22)\end{array}$ & $<0.001$ \\
\hline $\begin{array}{l}\text { Neurobehçet's disease, n } \\
\text { (\%) }\end{array}$ & $32,(4.8)$ & $13(4.6)$ & $19(5.0)$ & $\begin{array}{l}1.07(0.52- \\
2.21)\end{array}$ & 0.850 \\
\hline $\begin{array}{l}\text { Pathergy positivity ( } \mathrm{n}= \\
384), \mathrm{n}(\%)\end{array}$ & $233(60.7)$ & $\begin{array}{c}91 \\
(54.5)\end{array}$ & $\begin{array}{c}142 \\
(65.4)\end{array}$ & $\begin{array}{c}1.58(1.05- \\
2.39)\end{array}$ & 0.029 \\
\hline
\end{tabular}

Table 2. Comparison of the age according to the presence of clinical findings

\begin{tabular}{lccc}
\hline Findings & $\mathbf{n}$ & $\begin{array}{c}\text { Median age, years } \\
(\text { IQR })\end{array}$ & $\mathbf{p}$ \\
\hline GU & $(+)=571$ & $30.4(11.7)$ & $\mathbf{0 . 0 0 6}$ \\
& $(-)=94$ & $34.1(12.5)$ & \\
EN & $(+)=376$ & $30.3(11.4)$ & $\mathbf{0 . 0 2 5}$ \\
PPL & $(-)=289$ & $31.5(13.3)$ & \\
& $(+)=438$ & $30.5(12.0)$ & 0.569 \\
Ocular & $(-)=227$ & $30.5(11.1)$ & \\
& $(+)=217$ & $30.5(12.0)$ & 0.699 \\
Joint involvement & $(-)=448$ & $30.5(11.5)$ & 0.723 \\
& $(+)=328$ & $30.5(12.5)$ & \\
Vascular involvement & $(-)=337$ & $31.1(11.4)$ & 0.007 \\
& $(+)=144$ & $29.6(10.8)$ & 0.211 \\
Gl involvement & $(-)=521$ & $31.2(12.0)$ & \\
& $(+)=18$ & $27.8(10.9)$ & 0.374 \\
Headache, (n=581) & $(-)=647$ & $30.5(11.8)$ & \\
& $(+)=200$ & $30.4(12.9)$ & 0.160 \\
Neurobehçet's & $(-)=381$ & $31.0(11.6)$ & \\
disease & $(+)=32$ & $29.5(7.7)$ & 0.446 \\
Pathergy (n=384) & $(-)=633$ & $30.5(11.8)$ & \\
& Pozitive:233 & $30.8(12.6)$ & \\
\hline
\end{tabular}

Disclosure of Interests: None declared

DOI: 10.1136/annrheumdis-2019-eular.4612

\section{FRI0296 INPATIENT PREVALENCE, MORTALITY, EXPENDITURES AND COMORBIDITIES OF POLYARTERITIS NODOSA: NATIONWIDE INPATIENT SAMPLE 2014}

Patompong Ungprasert ${ }^{1}$, Karn Wijarnpreecha. ${ }^{2}$, Wisit Cheungpasitporn ${ }^{3}$, Charat Thongprayoon ${ }^{4}$, Paul Kroner ${ }^{2} .{ }^{1}$ Faculty of Medicine Siriraj Hospital, Mahidol University, Clinical epidemiology unit, Bangkok, Thailand; ${ }^{2}$ Mayo Clinic Florida, Jacksonville, United States of America; ${ }^{3}$ University of Mississippi Medical Center, Jackson, United States of America; ${ }^{4}$ Mayo Clinic Rochester, Rochester, United States of America

Background: Polyarteritis nodosa (PAN) is a systemic necrotizing vasculitis that characteristically affects medium-sized arteries of the intestine, kidneys and soft tissue [1]. Little is known about the inpatient burden, expenditures and association with comorbidities of PAN.

Objectives: To investigate the inpatient prevalence, expenditures and comorbidities of patients with PAN using a national inpatient database. Methods: Patients with PAN were identified from the Nationwide Inpatient Sample (NIS) database of the years 2014 using ICD-9 diagnostic code. NIS is a publicly available inpatient database that contained data of over 7 million hospital stays, which are a $20 \%$ stratified sample of over 4,000 non-federal acute care hospitals across all the regions of the United States (US). Data on patient characteristics, comorbidities, resource utilization and expenditures was collected. The primary outcome was determining the inpatient prevalence of PAN in hospitalized patients in the US. Secondary outcomes included determining inpatient mortality, inpatient morbidity (measured by shock, ICU admission and multi-organ failure), comorbidities, hospital length of stay (LOS) and total hospital costs and charges. The most common reasons for hospitalization were abstracted utilizing the top principal diagnoses in patients with PAN. A cohort of patients without PAN was also identified from the same database to serve as comparators for analysis of comorbidities. Multivariate regression analysis was used to adjust for age, gender, ethnicity, Charlson Comorbidity Index, income, hospital region, location, size and teaching status.

Results: A total of 5,255 patients with PAN were included in the study The mean age was 58.8 years, and $57 \%$ were female. The top reasons for hospitalization were PAN itself $(15.3 \%)$, sepsis $(6.9 \%)$, acute kidney injury $(4.8 \%)$ and acute respiratory failure $(2.5 \%)$. For the primary outcome, the inpatient prevalence of PAN was found to be 14.9 cases per 100,000 admissions. For secondary outcomes, patients with PAN displayed increased adjusted odds of mortality (OR:1.60, $\mathrm{p}<0.01)$, shock (OR:1.81, $p<0.01$ ), ICU admission (OR:2.06, $p<0.01$ ) and multiorgan failure (OR:3.45, p<0.01) compared to patients without PAN. Patients with PAN also displayed significantly higher hospital costs (additional adjusted mean [aAM]: $\$ 10,780, \quad \mathrm{p}<0.01$ ), hospitalization charges (aAM: $\$ 39,915, \quad \mathrm{p}<0.01$ ) and LOS (aAM: 4.2 days, $\mathrm{p}<0.01$ ) compared to patients without PAN Patients with PAN displayed a significant association with several comor bidities (Table 1).

Conclusion: The inpatient prevalence of PAN was higher than what would be expected from the overall prevalence. The mean total hospital costs and total hospitalization charges for patients with PAN were higher than patients without PAN. Analysis of comorbidities found significantly higher odds of several comorbidities even after adjusting for potential confounders.

\section{REFERENCE:}

[1] Forbess L, Bannykh S. Polyarteritis nodosa. Rheum Dis Clin N Am 2015;41:33-46

Table 1. Adjusted ORs comparing the prevalence of comorbidities between patients with PAN versus patients without PAN

\begin{tabular}{lccc}
\hline & Adjusted odds ratio & $\mathbf{9 5 \%} \mathbf{C l}$ & $\boldsymbol{p}$-value \\
\hline DVT & 2.07 & $1.60-2.66$ & $<0.01$ \\
PE & 2.12 & $1.62-2.78$ & $<0.01$ \\
AMI & 1.27 & $0.79-2.04$ & 0.32 \\
CHF & 1.10 & $0.92-1.32$ & 0.32 \\
Arrythmia & 1.05 & $0.86-1.29$ & 0.61 \\
Peripheral vascular disease & 0.86 & $0.61-1.19$ & 0.36 \\
Acute kidney injury & 4.14 & $3.54-4.85$ & $<0.01$ \\
Chronic kidney disease & 9.70 & $7.69-12.22$ & $<0.01$ \\
ESRD & 5.51 & $4.41-6.88$ & $<0.01$ \\
Intestinal perforation & 3.78 & $1.59-9.01$ & $<0.01$ \\
HBV infection & 5.01 & $2.80-8.95$ & $<0.01$ \\
HCV infection & 1.65 & $1.12-2.42$ & 0.01 \\
Sepsis & 1.87 & $1.54-2.28$ & $<0.01$ \\
\hline
\end{tabular}

Disclosure of Interests: None declared

DOI: 10.1136/annrheumdis-2019-eular.6577

\section{FRI0297 CLINICAL FEATURES, TREATMENT MODALITIES AND RELAPSE RATES IN GREEK PATIENTS WITH RETROPERITONEAL FIBROSIS}

Aliki Venetsanopoulou ${ }^{1}$, Evangelia Zampeli ${ }^{2}$, Sophia Christaki ${ }^{3}$,

Ourania Argyropoulou ${ }^{1}$, Kyriaki A. Boki ${ }^{4}$, Menelaos N. Manoussakis ${ }^{1}$, Foteini N. Skopouli ${ }^{3}$, Athanasios Tzioufas ${ }^{1}$, Haralampos M. Moutsopoulos ${ }^{5} .{ }^{1}$ School of Medicine, National and Kapodistrian University of Athens, Pathophysiology, Athens, Greece, ${ }^{2}$ Athens Medical School, Sotiria General Hospital, 3rd Internal Medicine Department, Athens, Greece; ${ }^{3}$ Euroclinic Hospital, Department of Internal Medicine and Clinical Immunology, Athens, Greece; ${ }^{4}$ Sismanoglion Hospital, 3Rheumatology Unit, Athens, Greece; ${ }^{5}$ Academy of Athens, Athens, Greece

Background: Retroperitoneal fibrosis (RPF) is a rare disease of unknown etiology characterized by deposition of fibro-inflammatory tissue around the infra-renal abdominal aorta. The process may involve adjacent structures leading to complications, the most frequent being ureteral obstruction [1]. RPF is mainly idiopathic (iRPF), yet it might be secondary to malignancies, infections, drugs, or radiotherapy [2]. Recent data argue that iRPF could be part of the $\operatorname{lgG}_{4}$-related diseases [3]. Diagnosis is aided by imaging studies (abdomen CT/MRI), but in patients with newly diagnosed RPF, excluding malignancy is mandatory [2].

Objectives: The aim of our study was a) to describe the presenting clinical, laboratory, imaging features and treatment modalities used in patients 